\title{
Social Connectedness, Academic, Non-Academic Behaviors Related To Self-Regulation among University Students in Saudi Arabia
}

\author{
Malek Jdaitawi ${ }^{1}$ \\ ${ }^{1}$ Deanship of Preparatory Year and Supporting Studies, University of Dammam, Saudi Arabia \\ Correspondence: Malek Jdaitawi, Self Development Department, University of Dammam, Saudi Arabia. Tel: \\ 96-653-799-5021. Email: mtmustafa@ud.edu.sa
}

Received: October 9, 2014 Accepted: November 20, 2014 Online Published: January 27, 2015

doi:10.5539/ies.v8n2p84

URL: http://dx.doi.org/10.5539/ies.v8n2p84

\begin{abstract}
Studies dedicated to examination of self-regulation posit a bi-directional association between self-regulation and other variables including social connectedness, self-efficacy and self-control. However, to date, studies of this caliber have only evidenced that self-regulation is a predictor of other variables. In the present study, the factors that predict self-regulation are examined among 209 undergraduate students in their preparatory year in the University of Dammam, Saudi Arabia. Collection of data was conducted in the school year's second semester. Based on the results, significant positive relations exist between social connectedness, self-efficacy and self-control, with self-regulation. Moreover, the results revealed that social connectedness and self-control are predictors of students' self-regulation, but not self-efficacy. Added to this, the result revealed a significant difference in the relationship between self-control and self-regulation among female students, with the other variables insignificant for both genders. Hence, it can be stated that higher education practitioners and academicians may focus on the assessment and the development of the students' skills in terms of self-regulation.
\end{abstract}

Keywords: social connectedness, academic-non-academic behaviors, self-regulation, university students

\section{Introduction}

Several studies have been dedicated to the determination of the factors that predict the success/failure of students in the past forty years. The studies' findings showed that academic as well as non-academic factors affect the learning and growth of students in terms of their social, emotional and personal development and that these factors may be considered as predictors. This is clear by the evidence provided by Hawkins, Catalano, Kosterman, Abbott, and Hill (1999), Battistich and Hom (1997) and Resnick et al. (1997) that after obtaining support and care from their environment, students are not as likely to immerse themselves in substance abuse, violence and adverse behaviors. Instead, they are more inclined to develop positive attitudes towards themselves and better social attitudes towards their peers (Shaps, Battistich, \& Solomon, 1997). According to majority of studies, schools providing support promote positive outcomes via the development of the students' connectedness perception (Resnick et al., 1997), sense of belonging (Baumeister \& Leary, 1995), community relations (Schaps, Battistich, \& Solomon (1997), promotion of achievement (Yusuf, 2011), self-efficacy (Maria, 2003), engaging attitude and positive leisure (Hutcherson et al., 2008) at the study environment.

Studies dedicated to exploring this field have covered factors that affect the connectedness of students and these include self-regulation, engagement, self-efficacy, time management, leisure attitude and positive attitude (e.g. Necati \& Sevil, 2010; Hutcherson, Seppala, \& Gross, 2008). Other studies like Resnick et al. (1997) showed that social connectedness facilitates the success of students whereas Maria (2003) and Lane et al. (2004) demonstrated that self-efficacy is the main factor in the success of students. Meanwhile, Necati and Sevil (2010) emphasized that time management is the road to students' success. Both engagement and positive attitude were supported by other researchers (e.g. Hall \& Hursch, 1982; Hutcherson et al., 2008) as significant factors in the learning and success of students.

\subsection{Problem Statement}

Educating the children and youth of the world is a requirement and ensuring their success is important to meet the increasing demands of the global economy and to bring about each individual's well-being and life quality. 
Several risk and protective factors have primarily been highlighted in terms of their relationship with adjustment life of adolescence. As such, it becomes important to consider that such relationship's cause and effect and the outcomes in the individual's life is complex. This is because a single risk factor may not significantly affect the adolescence development but the association between several factors would more likely affect the same (Raver, 2003; Miller \& Glinski, 2000; Bassarath, 2001). In this regard, some risk factors that result to maladaptive outcomes in the adolescents' lives are pinpointed in the domains of individual characteristics such as family, peers, schools, university and communities. The relevant issues are depressive symptoms, self-harming behavior, low self-efficacy and motivation, and disorders connected to anti-social behavior, peer involvement, and negative social link (low popularity and rejection from peers) (Bond, Toumbourou, Thomas, Catalono, \& Patton, 2005; Miller \& Glinski, 2000; Bassarath, 2001; Maehr \& Meyer, 1997).

Adolescent problems have been linked by several researches (e.g. Appleton, Chrisenson, \& Farlong, 2008; Raver \& Knitzer, 2002; Ackerman, Kogos, Youngstorm, Schoff, \& Izard, 1999) to decreased self-esteem, problem issues combined with negative peer influence and lackluster school performance, lack of social and emotional competencies and problems of social adjustment. The above scenario holds true in the context of Saudi Arabia as several studies (Abo-Zeid, Hifnawy, \& Abdel-Fattah, 2009; Abdel-Fattah, Asal, Al-Asmary, Al-Helali, Al-Jabban, $\&$ Arafa, 2004) have shown that adolescents are faced with a multitude of challenges in their lives. Some of these studies stressed on adolescent issues including emotional and behavioral disturbance, social issues, psychological pressure, lack of leisure time, average self-esteem level, self-injury, and moderate level of social connectedness (Abo-Zeid et al., 2009; Abdel-Fattah et al., 2004; Greydanus \& Shek, 2009; Al-Hattab, 2006; Al-Anazi \& Al-Shamli, 2011; Jdaitawi, Motawa, \& Al-Nabrawi, 2013). These issues lead to minimal inclination towards task performance, effective studying, memorizing details, strive towards success, selection of effective performance environment, setting and reaching goals and maintaining effort over time.

With regards to the risk and protectors variables in the life of student, majority of students have been revealed to display personality disorders, anti-social behavior, negative social connectedness, and little to no interest to participate in curricular activities, reading challenges, academic potential, depression, substance abuse and even suicide and harm as provided by Sawyer et al. (2001), Bassarath (2001), Miller and Glinski (2000), and Mansfield (2010). Thus, it can be contended that there are several factors that predict the outcomes and success of adolescent academic performance (Barber \& Rollins, 1990; Barnes \& Farrell, 1992; Pajares, 1997; Fremd \& Baltes, 2002; Joo, Bong \& Choi, 2000; Lee \& Robbins, 2000). In addition to this, there had been extensive studies concerning issues of psycho-social and cognitive factors and adolescent development, which related various aspects of such factors to several outcomes (Lee \& Robbins, 2000; R. Lee, Draper, \& S. Lee, 2001; Zimmerman, 2000; Mansfield, 2010; Chemers et al., 2001; Megan, 2009).

Some of these studies emphasized on some constructs as major factors that impact every aspect of the development of an adolescent-they are social connectedness, self-regulation, self-efficacy and self-control. In sum, researchers have hypothesized that social connectedness is among the crucial factors that result in higher well-being and eventually, an individual's happiness. The end result includes feeling a close relationship with peers, easy identification with other individuals, perception of others as friendly and approachable, taking part in social group and activities and stress on self-orientation and individualism (Cooper, 1999). Nevertheless, studies dedicated to determining the cause factors of the success of students in the Arab region are still few and far between. Only a few studies have been carried out regarding social-connectedness, self-regulation as well as other psycho-social and cognitive factors, and on top of this, the nature of such factors and their impacts on an adolescent's life is still largely unexplored (Stracuzzi \& Mills, 2010; Rasmussen, Wrosch, Scheier, \& Carver, 2006; Low \& Nelson, 2005). Moreover, studies dedicated to self-regulation and adolescent risk claimed that peer connectedness may play a role despite the lack of any particular study that focused on the relationship between connectedness and self-regulation. This study therefore attempts to contribute to literature by mainly examining the impact of social connectedness on self-regulation, cognitive and non-cognitive factors. Prior studies have been confined on diagnosing the relationship between the variables in individual educational settings in the Western countries and to the researcher's knowledge, no study has been dedicated to examining this relationship in the Arab region. Hence, this study attempts to contribute to literature by investigating these factors among university students in the context of Saudi Arabia.

\subsection{Purpose of the Study}

Despite the numerous evidence in prior literature concerning the cause factors of student's self-regulation, there still a need to conduct the study among adolescents (Danial, 2009; Twenge et al., 2002). Thus, this study contributes to literature in this field in the context of Saudi adolescents by assessing the causes of self-regulation learning among Saudi university students and the connection between social connectedness, self-regulation, 
self-efficacy and self-control. Specifically, the main objectives of the present study are:

1) To examine the relationship between social connectedness and self-regulation with cognitive and non-cognitive factors.

2) To identify the effect of social connectedness on the student's self-regulation.

3) To identify the relationship between social connectedness and the adolescent's cognitive and non-cognitive factors.

4) To identify the differences in the impact of social connectedness, self-efficacy and self-control upon self-regulation between male and female Saudi students.

\subsection{Significance of the Study}

Identifying factors that contribute to behavioral outcomes among students could assist the ministry's decision making regarding the professional advantages that can be obtained from the learning environment. Hence, this study attempts to extend literature in three ways; first, by determining the causes of self-regulation learning in a university environment; second, by determining the differences between the impact of social connectedness on the self-regulation level, in terms of cognitive and non-cognitive factors among Saudi university students and; third, conducting a comparative analysis of the reliability of the various models employed to different settings. The findings are expected to bring about explanations concerning the cognitive and non-cognitive outcomes of the adolescents as prior studies have been confined to diagnosing the relationship in an individual setting or a general discussion of the social connectedness role without conducting a comparative analysis of the various models' reliability employed to various settings.

\section{Literature Review}

\subsection{Adolescent Stage}

Adolescent refers to a stage in life where the childhood transitions into adulthood and it is characterized by major growth and development in terms of changes in physiology, cognitive, psychology and behavior, and crucial development tasks such as development of identity and independence (Lerner \& Villaruel, 1994). Adolescents experience several developmental challenges at differing levels including the increasing need for independence, sexuality evolvement, transition through education and employment, formation of advanced cognitive abilities, handling changing relationships with family, peers and social network, taking on legal responsibilities, and developing individual ethics and identity (Cameron \& Karbanow, 2003). Adolescence, as a concept, refers to one that is constructed socially rather than biologically and hence, its definitions may differ across cultures and over periods. Extant literature evidences various age ranges representing adolescence. The general definition contend that adolescence begins from as young as seven years extending to 18 years old until 22 years of age.

\subsection{Social Connectedness}

As a concept, connectedness has been a familiar topic in the field of psychology as pioneering studies have been dedicated to it. It is deemed as the relationship of the individual with the society and is crucial to psychological adjustment (Mcwhirter, 1990; Zachariah, 1994). In this regard, Lee and Robbins (1995) described social connectedness as the kind of relational scheme that signifies patterns found in interpersonal relationships. It was also explained to be a concept that is an enduring and ubiquitous self-sense in relationships to the world (Lee \& Robbins, 2000) enabling individuals to perceive themselves as a part of the human race and to identify themselves with people they gravitate to (Lee \& Robbins, 1995). In short, social connectedness refers to the way an individual relates with other individuals and his perception of himself in terms of networks and relationships.

Social connected individuals generally feel close to other individuals and they easily identify with them, perceive others as friendly and approachable and they commonly take part in social groups and activities. On the other hand, low connected individuals often experience negative feelings including loneliness, anxiety, jealousy, anger, depression, and low self-esteem. They think of themselves as pariahs and are others often misunderstand them as they separate themselves from society and face ample challenges in the social world (Denial, 2009). Although people in the latter type eventually manage to develop relationships with groups, they almost always lack an in-depth connection with themselves as well as with others (R. Lee, Draper, \& S. Lee, 2001). Thus researchers advocate the notion that social connectedness is a primary life aspect as it has been revealed to be related to higher levels of well-being in adolescents (Griffiths et al., 2007), the older generation (Fiori, Antonncci, \& Cortina, 2006; Litwin, 2001). In addition, Lee, Draper, and Lee (2001) also reported that social connectedness in college age population is related with heightened social involvement, positive perceptions of other individuals, 
effective relationship engagement (R. Lee, Draper, \& S. Lee, 2001), higher social competency and psychological well-being (Williams \& Gelliher, 2006) and high levels of esteem (Lee et al., 2001; Lee, Keogh, \& Sexton, 2002) Other studies such as Cohen and Wills revealed positive linkage leading to a perception of being protected from adverse life events while others like Julawong (2009) showed that it leads to confidence gain in coping with negative events. Contrastingly, low levels of social connectedness have been connected to depression in older individuals (Goden et al., 2009; Ingersall-Dayton, Morgan, \& Antonnucci, 1997) and other adverse feelings like isolation, maladaptive interpersonal behaviors and relationship dissatisfaction among college going adolescents (Lee et al., 2001). In sum, social connectedness has been reported to be significantly related to a sense of meaning in life while the contrary has been highlighted to be related to a sense of meaninglessness (Debats, 1995).

\subsection{Self-Regulation}

Self-regulation refers to thoughts and feelings and actions that are planned and employed by an individual for the achievement of personal aims (Zimmerman, 2000). Generally, it is a concept having broad implications and covering several interdependent factors such as affective capacities (emotions and feelings) and cognitive capacities (beliefs, perceptions and knowledge). Self-regulation is reported by Schunk and Ertmer (2000) to encapsulate setting of learning goals, focus on instruction, using effective strategies including ideas organization, effective use of resources, keeping track of performance, time management and high perception of abilities. Learning that is self-regulated is primarily a representation of the way learners improve their academic achievement via meta-cognitive, motivation and behavioral aspects (Zimmerman \& Schunk, 1989). In other words, learners characterized as practicing self-regulation plan, self-evaluate and self-monitor in a meta-cognitive manner at differing levels of the learning process while believing motivationally that they are individuals who are competent, self-efficacious, and independent, and they exert effort towards achieving academic objectives. Behaviorally, they choose structure and even create an environment for optimum learning (Zimmerman, 1986). Hence, to understand self-regulation of student's learning, researchers stressed on the examination of their motivational beliefs, self-efficacy and control beliefs (Abdallah \& Abu-Bakar, 2006; Schunk \& Pegy, 1999).

\subsection{Self-Efficacy}

Self-efficacy refers to the confidence levels of individuals on their ability to carry out actions or to achieve particular outcomes (Bandura, 1977, 1997). Bandura (1997) stated that beliefs of self-efficacy are based on the four information sources-enactive mastery experience/experience performing similar tasks, vicarious experiences, verbal persuasion, and physiological states. The concept of self-efficacy has been employed by researchers as a predictor of performance as its expectations can impact the initiation of behaviors and the persistence level employed in tackling difficulties faced while achieving tasks (Bandura, 1977). The positive self-efficacy-performance relationship has been widely acknowledged in literature and many studies have been dedicated to it in various settings (Chemers et al., 2001; Mooi, 2006). Specifically, Chemers et al.'s (2001) longitudinal study involved first year university students. They aimed to examine the impacts of academic self-efficacy and optimism upon the students' academic performance, stress, and health and school commitment. They included the predictor variables of high school GPA, academic self-efficacy, and optimism, and the moderator variables of academic expectations, and the students' ability of coping. The authors measured the variables at the end of the first academic quarter and linked them to classroom performance, personal adjustment, stress and health measured at the end of the school year. The study findings showed that academic self-efficacy and optimism significantly related to both performance and adjustment. In a related study, Lane et al., (2004) focused on the interconnections between self-efficacy, self-esteem, prior performance achievements, and academic performance among 205 post-graduate students. The study sample was required to complete measures of prior achievements, self-esteem, and self-efficacy at the onset of a 15-week course. The average grade of every student from the studied modules was utilized to measure performance. The findings revealed significant relationships between self-efficacy and self-esteem. Moreover, self-efficacy was revealed to mediate the performance accomplishments-academic performance relationship. The findings support the predictive effectiveness of self-efficacy measures in the context of academic environment.

\subsection{Self-Control}

Self-control refers to the individual's ability to transform states and responses such as thoughts, feelings and actions (Baumeister, 2002). It is significant in selection, pursuant, and disengagement of goals as a personality variable (Wrosch \& Freund, 2001). In terms of self-control, individuals possessing a strong capacity to control themselves can perform tasks better and they have higher degrees of interpersonal success (Tangney, Baumeister, 
\& Boone, 2004). Specifically, Tangney, Baumeister, and Boone (2004) contended that individuals having high personal capacity for self-control can highly adapt and they have the tendency to live a fulfilling life. In addition to this, self-control was linked with successful control over developmental life demands (Wrosch \& Freund, 2001). Adolescents characterized as having great self-control avoided conflicts between school and leisure and they have a higher life balance indicating that they are capable of coordinating their goals compared to those who have low self-control (Kuhnle et al., 2010a; Kuhnle, Hofer, \& Kilian, 2010b). More importantly, researchers such as Duckworth and Seligman (2006), Shoda, Mischel, and Peak (1990), and Wolfe and Johnson (1995) contended that the capacity for self-control predicts the academic achievement of students and hence, it is identical to self-regulated learning (Zimmerman, 2008). However, although the concepts developed in literature of self-regulated learning offers an explanation of strategies related with competent learning processes (Zimmerman, 2008), self-regulated learning is merely considered as a general capacity that is crucial for successful achievements in life aspects (Baumeister, 2002; Baumeister et al., 1998).

\subsection{The Relationship between Social Connectedness and Self-Regulation}

The concept of connectedness originated from the psychological context and is deemed to be the relationship of the individual with himself, his family and the society he lives in. Social connectedness is related to greater degrees of well-being among disadvantaged adults (Griffiths et al., 2007) as well as older adults (Fiori, Antonncci, \& Cortina, 2006; Litwin, 2001). In the university stage, social connectedness is linked to social involvement, good perception of others, ease of engaging in relationships (R. Lee, Draper, \& S. Lee, 2001), greater social competency and psychological health (Williams \& Gelliher, 2006), and high self-esteem (Lee et al., 2001; Lee, Keogh, \& Sexton, 2002). Social connectedness and social capital are primary determinants of mental and physical health and inequity as individuals are normally linked to their family, school, work and other community, group, club and organizations.

According to Brandtstadter (1998), adolescence refers to the occurring notion of personal future that interrelates with the self-regulation process-selection and enacting of behaviors that achieve goals and pertain to self. In a normative viewpoint, the self-regulation capacity achieves greater functioning levels (Freund \& Baltes, 2002) and can thus be considered as an important moderator of the actions of an individual (Baltes, Lindenberger, \& Staudinger, 2006). Specifically, Baltes et al. (2006) and Freund and Baltes (20020 contended that within the life span of an individual, the goals selection along with developing the means to attain goals and goal adjustment, in the face of barriers, constitutes a primary characteristic of an adolescent's successful ecological relationship. However, Brandstadter (1998) stressed that in the phase of adolescence, self-regulation has been largely overlooked.

Both school connectedness and self-regulation constitute the way in which the student experiences his environment and the way he perceives and behaviors in reaction to the environment (Brandstadter, 1998, p. 450). School connectedness perceptions are deemed to be a sense of safety and belonging to the school community and learning engagement (Witherspoon, Schotland, Way, \& Hughes, 2009). Students who perceive connections with their school environment are reported to be motivated in their academics and they have fewer tendencies to engage in antisocial behavior. Moreover, self-regulation including executive functioning aspects like attention, intentional behavior, emotional control, etc. along with metacognition reflects the ability of the student to motivate and direct themselves and to reflect on their thoughts and actions in ways that is invaluable and intentional (Zimmerman \& Schunk, 1989). In this regard, self-regulation affects social emotional skills as well as academic success in the context of schools. According to Baumeister and Leary (1995), developing and maintaining social bonds is among the most effective motives of human beings. Studies support the role of social connections in various functioning domains. When individuals' social connectedness sense is challenged, their self-regulation ability is negatively impacted; for example, their IQ performance takes a dip (Beumeister, Twenge, \& Nuss, 2002). On the basis of the above discussion, it can be stated that social connectedness benefits the individual's relationships as well as enhances self-regulation. Nevertheless, in literature, the positive effect of social connectedness on self-regulation has not been empirically confirmed (Baumeister \& Stillman, 2007; Wittaker, 2008).

Despite the fact that extant literature indicates the significance of social connectedness in the adolescent stage (Sundler \& Dahlberg, 2009; William \& Galliher, 2006), not a single study focused on its impact on self-regulation in the stage of adolescence. Based on the limited research in this field, this paper's findings stress on the need to examine the impact of social connectedness on self-regulation and other student's life variables as recommended by Wittaker (2008). 


\subsection{Relationship between Social Connectedness, Cognitive and Non-Cognitive Factors}

Interactions within and between the biological context of an individual and his families, peers and school subsystems create the basis for their development (Bronfenbrenner, 1977). Along the same line of contention, social cognitive theory (Bandura, 1986, 1999) stressed on the important role of vicarious learning, learning by behavior observance of trusted others, in the development of children's self-efficacy. By observing the conversations among their family members, children increasingly develop their confidence to utter different words. On this basis, it can be stated that social connectedness and self-efficacy are interlinked. The need to belong is coupled by a need for regular contact and perception that the interpersonal relationship is solid, ongoing and has affective concern (Baumeister \& Leary, 1995). Thus, the need to belong may assist in explaining various human behavior, cognitive, motivational processes and emotions. Furthermore, several prior studies in this field contended that connectedness entails three kinds of dynamically related dimensions namely cognitions, emotions and behaviors (Fredricks, Blumenfeld, \& Pairs, 2004; Glanville \& Wildhagen, 2007). Specifically, Fredricks et al. (2004), Jimerson et al. (2003) and Ainley (1993) described cognitive dimension as the student's personal investment and learning approaches and self-regulatory strategies-it is operationalized as the perception and beliefs concerning the self, school and peers including strategies geared towards self-efficacy, motivations and academic aspirations. This feeling of belonging may directly and significantly affect the motivation of students (Goodenow, 1993b). For instance, both perceived support and the sense of belonging are predicted to increase the beliefs of the students concerning their success and eventually, their academic motivation. The sense of belonging in the classroom results in the development of a sense of school community, which adds to the positive behavioral, psychological, and social outcomes of students like achievement motivation, and competence and helps decrease negative outcomes like delinquency and use of drugs (Battistich, Solomon, Watson, \& Schaps, 1997). Several researchers in the field of education are of the consensus that the need for belonging is among the most crucial needs of students' functioning in different learning contexts (Connell \& Wellborn, 1991; Deci \& Ryan, 1991; Finn, 1989; Osterman, 2000). In a study involving college students by Wittaker (2008), social connectedness was found to be related to perceived stress and health symptoms. Similarly, Pittman, and Richmond (2007) reported that school belonging may be related to academic motivation. Also, Freeman et al. (2007) studied the relationship between university students' sense of school belonging and academic achievement along with other variables. Their study sample comprised 238 first semester freshman. Their findings showed that student belonging related to academic self-efficacy, intrinsic motivation to achieve and value of task. They elaborated that students who had a sense of school belonging also felt that their instructors are more perceptive of them, and they are more organized and encouraging. On the other hand, students who lack the sense of school belonging felt their instructors to be cold.

In sum, prior studies claimed that social connectedness is among the primary factors that lead to the students' successful achievements in university life. High connectedness to university have been reported to lead to greater levels of self-efficacy, higher levels of academic motivation for achievement, which result in successful students and high scores in academic achievement. However, studies dedicated to connectedness and its relationship to cognitive and non-cognitive factors among university students are still few and far between and needs further examination (Wittaker, 2008; Heiman, 2004).

\subsection{The Effect of Variables on Self-Regulation Based on Students' Characteristics}

Donald, Dower, Correa-Velez, and Jones (2006) stated that social connectedness is related with health and is a protective factor that combats distress and its results. Additionally, other researchers (R. Lee, Draper, \& S. Lee, 2001) indicated that social connectedness in college age population is linked to social involvement positive perception of peers, and easier engagement in relationships. Others related the construct to higher social competency and psychological health (e.g. Williams \& Galliher, 2006), and increased self-esteem levels (Lee et al., 2001; Lee, Keough, \& Sexton, 2002; Lee \& Robbins, 2000). Still some other researchers like Pittman and Richmond (2007), Freeman et al. (2007), and Mueller (2008) showed that school belonging has a crucial role in achievement motivation and psychological adjustment of college students and is related with the perceptions of the students of their faculty. They added that this may differ according to the students' individual differences. For example, females were found to have higher levels of social connectedness compared to their male counterparts and the relationship between social connectedness and perceived stress was reported to be higher in the latter group (Moller, Fouladi, McCarthy, \& Hatch, 2003; Lee et al., 2002). Additionally, social connectedness at a young age was reported to predict health and health risk behaviors in later life (Bond et al., 2007). Low level of social connectedness was linked to depression in older adults (Golden et al., 2009; Ingersoll-Dayton, Morgan, \& Antonucci, 1997) and with perceptions of isolation, maladaptive interpersonal behaviors and dissatisfaction in relationships (Lee et al., 2001), particularly in college adolescents. Moreover, academic self-efficacy and 
optimism were found to be significantly linked to performance and adjustment by Chemers et al. (2001) and adolescents with high self-control avoided conflicts between school and leisure and had high life balance. These indicate that such adolescents are more capable of coordinating their goals more than their peers (Kuhnle et al., 2010a; Hofer \& Kilian, 2010b). Despite the many studies that report the significant differences of the effect of social connectedness on other variables between genders, more research is called for to confirm such differences in the context of college students.

\section{Method}

\subsection{Research Design}

This study used a quantitative survey method for its research design. According to Babbie and Mouton (2001), survey refers to the research method that scrutinizes the accuracy of phenomenon and provides a precise description of what the research observes. The survey method is considered as the most appropriate method that is available to be utilized for data collection in order to describe a large population. Bassey (1995) contended that such surveys are excellent methods used to measure attitude and orientations that prevail in a large population. The employment of quantitative method is suitable in this present study as it allows the research to obtain snapshot views and attitudes of respondents with regards to the phenomenon under examination (Sekaran, 2003). Moreover, prior studies dedicated to studying the relevant variables of the present study also employed a quantitative method (Twenge et al., 2002). In this regard, Stacks (2002) described survey as a method that gathers in-depth information concerning the attitudes and beliefs of respondents, specifically those involving large populations. Because the number of students in this study is significant, it is challenging to gather authentic and objective data through other methods.

\subsection{Population/Sample}

The study participants consist of students enrolled in Saudi universities. Owing to the impossibility of including the entire students, an appropriate sampling technique is required. The researcher chose a subject of a larger number of observations for this. Specifically, 209 undergraduate students were selected via stratified sampling method-a method that guarantees equal opportunity of every student to be chosen to represent the university faculties. The stratified random sampling was used to ensure the right proportion of representation of population sub-groups. Robson (1993) described stratified sampling as the optimum choice as the means are likely to be of close proximity to the mean of the overall population. Also, Leary (1995) supported that stratified random sampling extensively reflects the whole population's characteristics. The study sample comprised of preparatory year students enrolled in the faculties of Medicine, Engineering and Science in the University of Dammam, Saudi Arabia. They are characterized by similar student demographics with little variation in teaching and learning processes.

\subsection{Outcome Measurements}

This study employed several measures; in particular, social connectedness was measured through the social connectedness scale proposed by Lee and Robbins (1998) to highlight the level of interpersonal closeness that is felt between the individual and his social network, and the level of difficulty in sustaining such closeness. For this purpose, students were required to respond to 20 questions on a five point likert scale, which ranged from 1 depicting strongly disagree to 5 depicting strongly agree. High score indicates a corresponding high connection between the individual and his network. This scale showed high internal reliability having a high alpha coefficient of 0.92 and high validity on a three factor model (Lee \& Robbins, 1998). LASSI, a scale adopted from the learning and study strategies inventory proposed by Weinstein, Schulte, and Palmer (2002) was used to measure self-regulation. The scale consisted of 32 questions that assessed four main factors, with the entire items rated from 1 depicting strong disagree to 5 depicting strongly agree. In addition, self-efficacy was measured with the help of the general self-efficacy scale of 10 items developed by Schwarzer and Jerusalem (1995) for the prediction of tackling daily hassles and adapting after going through stressful life events. Statements to describe this factor included, "I can always manage to solve difficult problems if I try hard enough; I can usually handle whatever comes my way". Furthermore, self-control scale consisting of 26 items developed by Tangney, Baumeister, and Boone (2004) was used to measure self-control. Such scale was developed for the prediction of the students' capacity to modify them and adapt to generate a superior optimal alignment between self and the environment. The items were measured on a 5-pointlikert scale ranging from 1 depicting not at all like me to 5 depicting very much like me.

\subsection{Procedure}

The study sample comprised 209 students of both genders (male and female) enrolled at the University of 
Dammam in the faculties of medicine, engineering and science. Data collection was carried out at the end of the second semester of the year 2013/2014. The researcher approached the students at the end of a timetable session and explained the aim behind the study.

\subsection{Descriptive Statistics and Confirmatory Factor Analysis}

This study conducted the confirmatory factor analysis on the variables to assess the robustness of the measurement model. Four latent variables were included in the study and all four variables were exposed to confirmatory factor analysis. The study examined the variables in terms of their convergent validity, discriminant validity as well as Cronbach's alpha. The entire CFA was conducted via AMOS to confirm the overall acceptability of the measures specifically with the use of the Chi-square statistics, ratio, RMSEA, CFI and TLI. These values were employed as they are not as sensitive to sample size as compared to their counterparts (Fan, Thomson, \& Wang, 1999). Both the confirmatory fit index (CFI) and TLI values of $\geq .90$ and RMSEA value of $\geq .08$ indicate the model fit adequacy, while normed $\left(\chi^{2}=\mathrm{chi} \geq .5\right.$ indicates adequacy of the model fit. In this regard, some items in the first model of the exogenous and endogenous variables were found to load weakly to the latent variables. These weak items were deleted after which the results of the variables measurement models generated an appropriate fit statistics for the entire indices values. Additionally, the coefficients scale reliabilities were all acceptable at $>.70$. The measurement models results for the entire variables are presented in Table 1 . The entire variable reported more than average descriptive statistics scores and skewness and kurtosis statistics remained within the acceptable value of 1.96 , indicating normal distribution of data.

Overall Measurement Model Fit for Research Model

\begin{tabular}{lllll}
\hline Fit Index & Social Connectedness & Self-Regulation & Self-Efficacy & Self-Control \\
\hline Cronbach Alpha & .95 & .87 & .92 & .84 \\
$($ RMSEA $)$ & .077 & .076 & .070 & .077 \\
$($ CFI $)$ & .943 & .911 & .987 & .942 \\
$($ TLI) & .932 & .902 & .978 & .934 \\
$\left(\chi^{2}=\right.$ chi $)$ & 2.245 & 2.209 & 2.018 & 2.22 \\
Mean & 3.32 & 3.27 & 3.25 & 3.17 \\
SD & .89 & .88 & .96 & .93 \\
Skewness & -.583 & -.455 & -.406 & -.245 \\
Kurtosis & .135 & .034 & -.297 & -.381 \\
\hline
\end{tabular}

\section{Results}

Data analysis is described as a process comprising of several stages like coding of responses, cleaning, data screening, and choosing the strategy for data analysis (Churchill \& Lacobucci, 2002; Sekaran, 2003). In the present study, data analysis and hypotheses testing entailed the use of statistical tools and methods of Statistical Package of Social Science (SPSS) and Structural Equation Modeling (SEM). In addition to the above analyses, bivariate correlation was employed to investigate the relationship between the study variables (social connectedness, self-regulation, self-efficacy and self-control. According to the results, a positive significant correlation exists between social connectedness and self-regulation $(\mathrm{r}=.722, \mathrm{p}=.000)$, self-efficacy $(\mathrm{r}=.601$, $\mathrm{p}=.000)$ as well as self-control $(\mathrm{r}=.598, \mathrm{p}=.000)$. A positive significant correlation was also found between self regulation and self-efficacy $(\mathrm{r}=.619, \mathrm{p}=.000)$, and self-control $(\mathrm{r}=.550, \mathrm{p}=.000)$ and between self efficacy and self-control $(\mathrm{r}=.503, \mathrm{p}=.000)$. It can therefore be concluded that the entire variables are positively correlated with each other.

The next analysis conducted was the multivariate modeling technique as this method is capable of including multiple predictors and variables criteria in a single model. Owing to the significant number of variables items in the study, the researcher selected a construct model for multidimensional variables by parceling items as recommended by Little, Cunningham, Shahar, and Widaman (2002). This was motivated by the aim to realize acceptable indicators ratio to sample size (Bagozzi \& Edward, 1998). Moreover, the parceling technique was also adopted as the study is focused on the relationship between latent variables as opposed to the factor structure of the measurement model. Hence, the items were randomly divided into parcels and were considered 
as indicators of model 1 latent variables. The obtained significant minimum fit chi-square statistic of $(250.794$ and $p=0.000$ ) indicated imperfect model fit and implying that the model may be inadequate. Nevertheless, Diamantopoulos and Siguaw (2000) stressed on the sensitivity of the chi-square statistic to multivariate normality and sample size. Hence, the ratio of chi-square and degree of freedom $\left(\chi^{2}=\right.$ chi) was used as recommended by Bollen and Long (1993), where a value ranging from 2-5 is considered to represent a good fit (Kelloway, 1998). In this study a value of 1.959 was achieved for the structural model. The root mean square error of approximation or RMSEA has its basis on the residuals analysis, with values lower than 0.08 representing a better data fit (Dimantopoulos \& Siguaw, 2000). In this study, the model obtained a value less than 0.08 (0.68) and this fell within the recommendation. Moreover, the CFI and TLI values were found to be 0.951 and 0.942 respectively, values that fall within the suggested value of 0.90 , and thus indicating that the structural model based on the four indices showed adequate fit. Figure 1 presents the structural model along with its ML parameter estimates. The t-statistic for individual structural coefficients were studied to confirm whether or not they are significantly correlated on the basis of $(t \geq 1.96 ; p<0.05)$. From Table 2 , the $t$-value shows positive significant relationship between social connectedness and self-efficacy $(7.42 ; \mathrm{p}<0.05)$, self control $(7.26 ; \mathrm{p}<0.05)$, and a positive significant relationship between self-efficacy and self-control $(7.84 ; \mathrm{p}<0.05)$ and hence, hypothesis 1 is supported.

The second group entailed the evaluation of whether or not social connectedness, self-efficacy and self-control were predictors of self-regulation among Saudi students. According to the results, social connectedness positively predicted the students' self regulation $(\beta=.36, p=.032)$, self-control positively predicted self-regulation ( $\beta=.50, \mathrm{p}=.000$ ) but self-efficacy did not significantly predict students' self-regulation ( $\beta=.20$, $\mathrm{p}=.074)$. The third analysis involved the comparison of the social connectedness, self-efficacy and self-control effects upon self-regulation between the two genders. Data was analyzed via multiple group analysis (males and females), the highest-likelihood structural equation modeling. The model showed a good data fit with the value of chi-square value of 2.541 for the structural model. In addition, the value of the RMSEA was 0.08 , which showed better data fit while values for CFI and TLI were 0.849 and 0.820 respectively. The analysis results displayed a significant path in the female model regarding the effect of self-control on self regulation but the rest of the variables relationships for both genders were insignificant. Therefore, the fourth hypothesis was rejected and the fifth one is partially supported.

Table 1. Univariate correlation

\begin{tabular}{lllll}
\hline Variables & 1 & 2 & 3 & 4 \\
\hline Social Connectedness & 1 & .722 & .601 & .598 \\
Self-Regulation & .722 & 1 & .619 & .550 \\
Self-Efficacy & .601 & .619 & 1 & .503 \\
Self-Control & .598 & .550 & .503 & 1 \\
\hline
\end{tabular}

Table 2. Structural equation modeling: relation analysis

\begin{tabular}{llll}
\hline H & Structural Relation & C.R. & t.value \\
\hline H1 & Self Connectedness->Self-Regulation & 2.148 & $.032^{*}$ \\
H2 & Self-Efficacy->Self-Regulation & 1.786 & .074 \\
H3 & Self-Control->Self-Regulation & 3.588 & $.000^{*}$ \\
\hline
\end{tabular}

Table 3. Structural equation modeling: relation analysis

\begin{tabular}{llllll}
\hline \multirow{2}{*}{$\mathrm{H}$} & \multirow{2}{*}{ Structural Relation } & \multicolumn{2}{c}{ Male } & \multicolumn{2}{c}{ Female } \\
\cline { 3 - 6 } & & C.R. & t.value & C.R. & t.value \\
\hline H1 & Self Connectedness->Self-Regulation & .031 & .990 & .22 & .829 \\
H2 & Self-Efficacy->Self-Regulation & .143 & .886 & 1.443 & .149 \\
H3 & Self-Control一>Self-Regulation & .112 & .911 & 2.559 & $.010^{*}$ \\
\hline
\end{tabular}




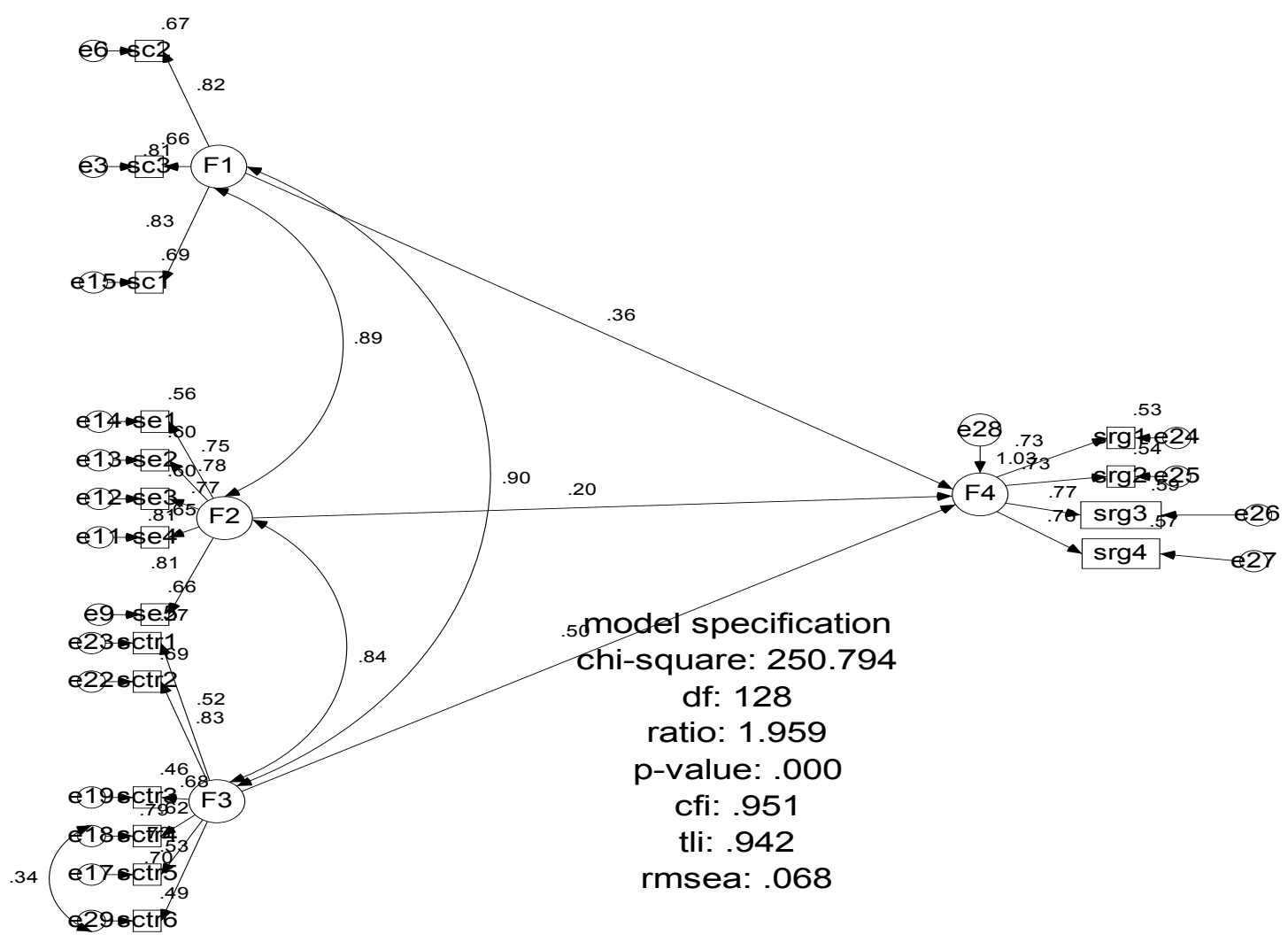

Figure 1. Structural model

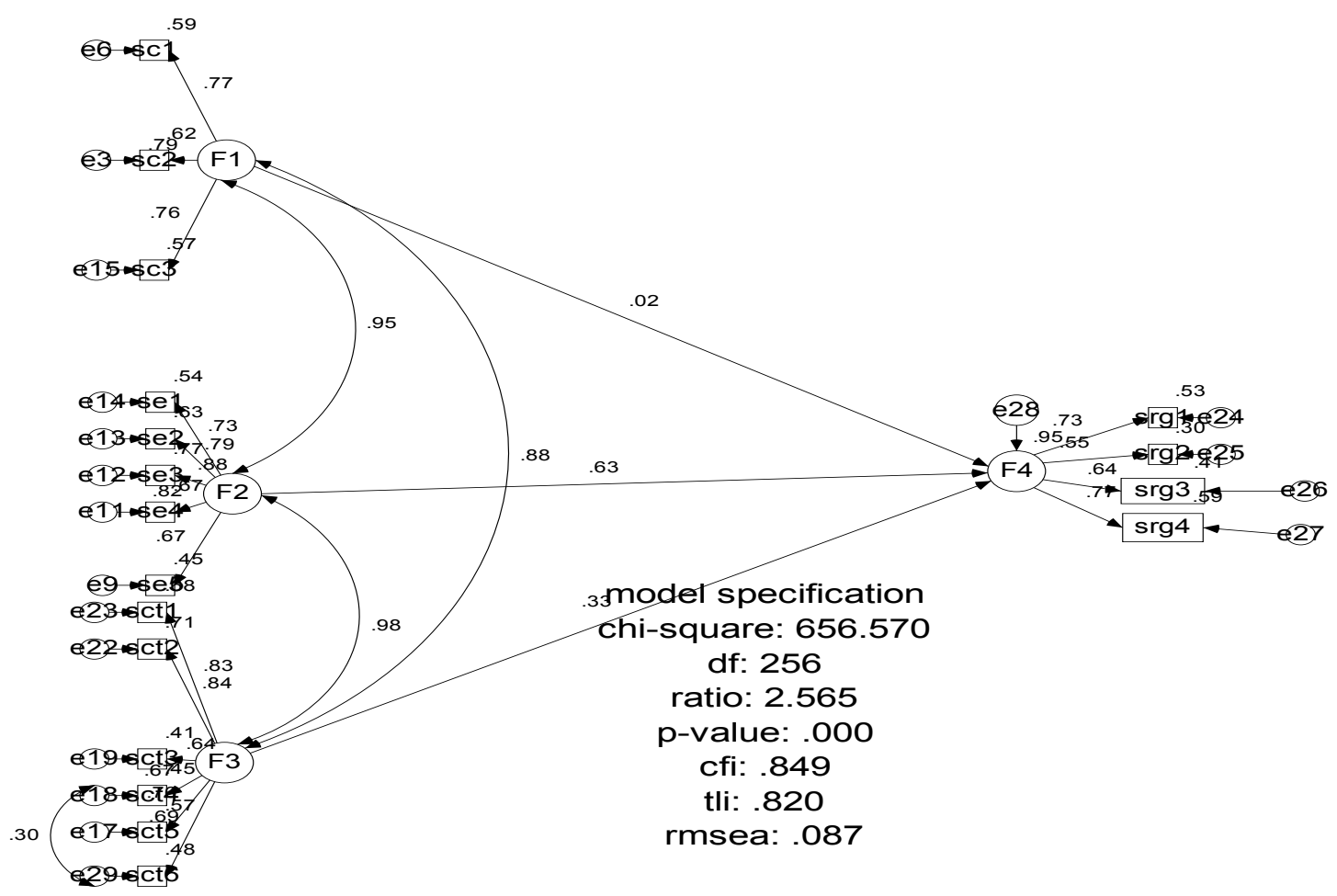

Figure 2. Male 


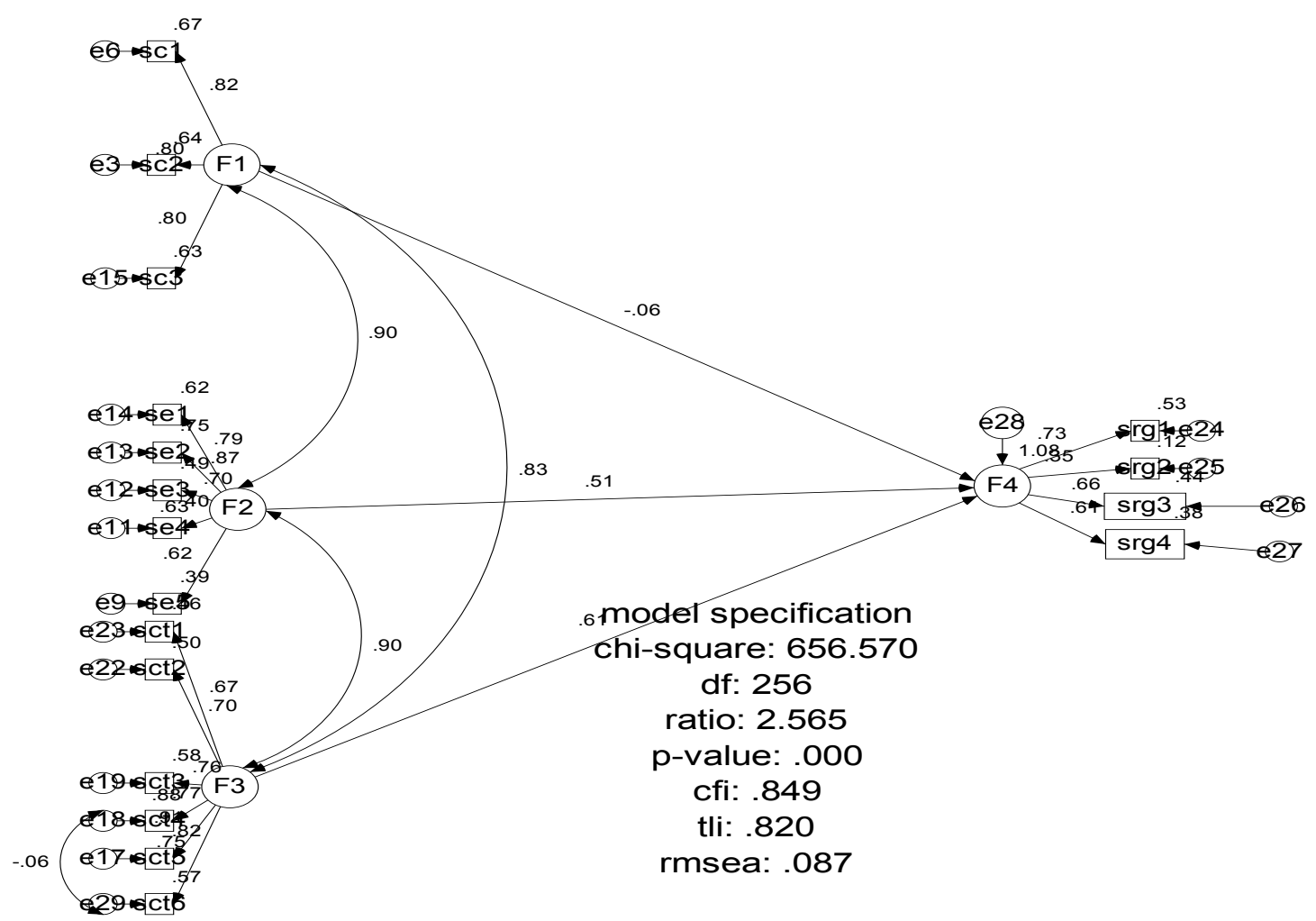

Figure 3. Female

\section{Discussion}

This study has several aims; first, to model social connectness, self-regulation, self-efficacy and self-control relationship; second, to evaluate the impact of social connectedness, self-efficacy and self-control on self-regulation; and lastly, to compare the significant differences of the impact of social connectedness, self-efficacy and self-control on self-regulation between the two groups of students (male and female). The results fully supported the hypothesized relationships between social connectedness, self-efficacy and self-control with self-regulation. This is consistent with prior studies that investigated the relationships between the variables (e.g. Witherspoon et al., 2009; Whittakur, 2008; Hamedani, 2013; Pintrich \& DeGroof, 1990).The second and third hypotheses were focused on the social connectedness, self-efficacy and self-control prediction of self-regulation-based on the results, both hypotheses were partially confirmed. Specifically, social connectedness and self-control was found to predict self-regulation but not self-efficacy. Previous studies showed that social connectedness is the top human motive and in instances where individuals' sense of social connectedness is threatened, their self-regulating ability is negatively affected. Therefore, students in the present study showed higher social connectedness level, which could play a significant role in predicting self-regulation. In addition, self-control was found to be a predictor of self-regulation suggesting that when individuals are able to control their baser impulses over time and in various situations, they can override negative impulses and this is consistent with studies dedicated to self-regulation and self control relationship such as Baumeister, Bratslavsky, Muraven, and Tice (1998), Baumeister and Heatherton (1996), Muraven, Tice, and Baumeister (1998), and Schmeichel and Baumeister (2004). However, on the contrary to prior studies, the study findings showed self-efficacy not to predict self regulation and this may be attributed to the fewer score that the students obtained -as they feel less efficacious to achieve their tasks in class. According to Schunk (1990), students having low self-efficacy for learning may steer clear of tasks while those who are high self-efficacious take part in solving tasks. He also stated that when students are faced with academic challenges, those who have high self-efficacy extend effort and persist more than those who have low self-efficacy.

This study also investigated the differences to which social connectedness, self-efficacy and self-control are related with self-regulation between the male and female students. Prior studies showed a positive relationship between social connectedness, self-efficacy, and self control with self-regulation but such relationship may not be as significant when gender differences are analyzed. In the present study's findings, self-control was found to 
relate with self-regulation among female students not males. This may be explained by the notion that while both genders are concerned of their needs and others and their experiences lead to their greater involvement in the class and activities, in general, female students are more likely to take part in self-deprecating humor when tackling adversities and absurdities (Lefcourt, 2001) in order to gain the group support. This may be why women are successful in choosing or developing contexts that suit their personal needs and values indicating that they have environmental mastery over their male counterparts. In sum, the present study is a pioneering study that attempted to assess the complex relationship between social connectedness, self-efficacy and self-control, and self-regulation. Prior research did not examine whether or not the present study's variables are predictors of self-regulation, particularly social connectedness. This study showed the extent to which social connectedness, self-efficacy and self-control may impact self-regulation. Its major contribution is the inclusion of gender in the analysis, as prior failed to include the differences between study variables in terms of gender in the independent-dependent variables relationship, particularly as the result was significant. Like other studies, this study has some limitations. First and foremost, the entire data was gathered from self-report measures that are susceptible to inflated biases due to the influences of social desirability. Second, the research design adopted by this study is a correlational research design and hence, for more in-depth findings and for further directionality of variables effects, future researches can employ the longitudunal and experimental design. Lastly, the study sample is confined to students studying in the University of Dammam, Saudi Arabia limiting the findings generalizability. Therefore, future studies could include other students from other Saudi universities.

\section{Acknowledgments}

This work was supported by Deanship of Scientific Research, University of Dammam, under award number (2014140)".

\section{References}

Abdel-Fattah, M., Asal, A., Al-Asmary, S., Al-Helali, N., Al-Jabban, T., \& Arafa, M. (2004). Emotional and Behavioral Problems Among Male Saudi School Children and Adolescents Prevalence and Risk Factors. German Journal of Psychiatry. Retrieved from http://www.gjpsy.uni-goettingen.de

Abdullah, M. (2008). Childrens implicit theories of intelligence: Its relationships with self-efficacy, goal orientations, and self-regulated learning. The International Journal of Learning, 15(2), 47-56. Retrieved June 3, 2014, from http://jamiesmithportfolio.com/EDTE800/wp-content/Self-Efficacy/Abdullah.pdf

Abu-Zeid, A., Hifnawy, T., \& Abdel-Fattah, M. (2009). Health Habits and Behaviour of Adolescent School Children, Taif, Saudi Arabia. Eastern Mediterranean Health Journal, 15(6), 1525-1534.

Ackerman, B. P., Kogos, J., Youngstrom, E., Schoff, K., \& Izard, C. (1999). Family instability and the problem behaviors of children from economically disadvantaged families. Developmental Psychology, 35, 258-268.

Al-anazi, H., \& Al-Shamli, A. (2011). Sensation Seeking and Delinquency Among Saudi Adolescents. European Journal of Social Sciences, 21(2), 265-286. Retrieved April 3, 2014, from http://www.europeanjournalofsocialsciences.com/issues/EJSS_21_2.html

Al-Hattab, A. (2006). Self Esteem and Writing Achievement of Saudi EFL Students in Secondary Schools (Unpublished Master thesis). Taibah University, Saudi Arabia.

Appleton, J., Christenson, S., \& Furlong, M. (2008). Student engagement with school: Critical conceptual and methodological issues of the construct. Psychology in the Schools, 45(5), 369-386. http://dx.doi.org/10.1002/pits.20303

Armstrong, S., \& Oomen-Early, J. (2009). Social connectedness, self-esteem, and depression symptom-moatology among collegiate athletes versus non-athletes. Journal of American College Health, 57, 521-526. Heldref Publication.

Babbie, E., \& Mouton, J. (2001). The practice of social research. Cape Town: Oxford University Press.

Bagozzi, R., \& Edwards, J. (1998). A general approach for representing constructs in organizational research. Organizational Research Methods, 1, 45-87. http://dx.doi.org/10.1177/109442819800100104

Baltes, P., Lindenberger, U., \& Staudinger, U. (2006).Lifespan theory in developmental psychology. In W. Damon (Series Ed.), \& R. M. Lerner (Vol. Ed.), Handbook of child psychology: Vol. 1. Theoretical models of human development (6th ed., pp. 569-664). Hoboken, NJ: Wiley.

Barber, B. K., \& Rollins, B. C. (1990). Parent-adolescent relationships. Lanham, MD: University Press of America. 
Barnes, G. M., \& Farrell, M. P. (1992). Parental support and control as predictors of adolescent drinking, delinquency, and related problem behaviours. Journal of Marriage and the Family, 54, 763-776. Retrieved May 15, 2014, from http://www.rti.org/publications/abstract.cfm?pubid=743

Bassarath, L. (2001). Conduct disorder: A bio-psychosocial review. Canadian Journal of Psychiatry, 46, 609-616. Retrieved August 1, 2014, from http://www.ncbi.nlm.nih.gov/pubmed/11582821

Bassey, M. (1995). Creating Education Through Research. New York: Kirklington Press

Battistich, V., \& Hom, A. (1997). The relationship between students' sense of their school as a community and their involvement in problem behaviors. American Journal of Public Health, 87(12), 1997-2001. Retrieved April 7, 2014 from http://www.ncbi.nlm.nih.gov/pmc/articles/PMC1381243/

Baumeister, R. F., \& Heatherton, T. F. (1996). Self-regulation failure: An overview. Psychological Inquiry, 7, $1-15$.

Baumeister, R. F., Bratslavsky, F., Muraven, M., \& Tice, D. M. (1998). Ego depletion: Is the active self a limited resource? Journal of Personality \& Social Psychology, 74, 1252-1265. Retrieved June 2, 2014, from http://www.psy.lu.se/upload/psykologi/pdf/strength_model1.pdf

Baumeister, R. F., Heatherton, T. F., \& Tice, D. M. (1994). Losing Control: How and Why people fail at Self-Regulation. Academic Press: San Diego.

Baumeister, R., \& Leary, M. (1995). The need to belong: Desire for interpersonal attachments as a fundamental human motivation. Psychological Bulletin, 117(3), 497-529. Retrieved May 3, 2014 from http://persweb.wabash.edu/facstaff/hortonr/articles\%20for\%20class/baumeister\%20and\%20leary.pdf

Bollen, K. A., \& Long, J. S. (1993). Testing structural equations. Newbury Park, CA: Sage Publications.

Bond, L., Toumbourou, J. W., Thomas, L., Catalano, R. F., \& Patton, G. (2005). Individual, family, school, and community risk and protective factors for depressive symptoms in adolescents: A comparison of risk profiles for substance use and depressive symptoms. Prevention Science, 6(2), 73-88. http://dx.doi.org/10.1007/s11121-005-3407-2

Brandtstatdter, J. (1998). Action perspectives on human development. In W. Damon (Series Ed.), \& R. M. Lerner (Vol. Ed.), Handbook of child psychology: Vol. 1. Theoretical models of human development (5th ed., pp. 807-863). New York: Wiley.

Bronfenbrenner, U. (1977). Toward an experimental ecology of human development. American Psychologist, 32, 513-531. http://dx.doi.org/10.1037/0003-066X.32.7.513

Cameron, G., \& Karabanow, J. (2003). The nature and effectiveness of program models for adolescents at risk of entering the formal child protection system. Child Welfare, 82(4), 443-474.

Carnes, M. (2001). Humor. In J. Worell (Ed.), Encyclopedia of women and gender (Vol. 1, pp. 601-609). San Diego, California: Academic Press.

Chemers, M. M., Hu, L., \& Garcia, B. F. (2001). Academic self-efficacy and first-year college student performance and adjustment.Journal of Educational Psychology, 93, 55-64. Retrieved July 5, 2014, from http://psycnet.apa.org/index.cfm?fa=buy.optionToBuy\&id=2001-16705-006

Churchill, G. A., \& Iacobucci, D. (2002). Marketing research: Methodological foundations (8th ed.). Orlando: Harcourt College Publishers.

Cohen, S., \& Wills, T. A. (1985). Stress, social support, and the buffering hypothesis. Psychological Bulletin, 98 , 310-357

Connell, J. P., \& Wellborn, J. G. (1991). Competence, autonomy, and relatedness: A motivational analysis of self-system processes. The Minnesota Symposia on Child Development: Self-Processes and Development, 23, 43-77.

Cooper, C. R. (1999). Multiple selves, multiple worlds: Cultural perspectives on individuality and connectedness in adolescent development. In A. S. Masten (Ed.), Cultural Processes in Child Development: The Minnesota Symposia on Child Psychology (Vol. 29, pp. 25-57). Mahwah, NJ: Lawrence Erlbaum.

Debats, D. L. (1995). Experiences of meaning in life: A combined qualitative and quantitative approach. British Journal of Psychology, 86, 359-375.

Deci, E. L., \& Ryan, R. M. (1991). A motivational approach to self: Integration in personality. Nebraska Symposium on Motivation: Perspectives on Motivation, Lincoln, NE., 38, 237-288. 
Denial, L. (2009). The relationship of connectedness and control. Research Project. Jefferson City, TN.

Diamantopoulos, A., \& Siguaw, J. (2000). Introducing LISREL. London: Sage Publications.

Donald, M., Dower, J., Correa-Velez, I., \& Jones, M. (2006). Risk and protective factors for medically serious suicide attempts. Australian and New Zealand Journal of Psychiatry, 40, 87-96. http://dx.doi.org/10.1080/j.1440-1614.01747

Duckwoth, A., \& Seligman, M. (2005). Self-discipline outdoes IQ in predicting academic performance of adolescents. American Psychological Society, 16(12), 939-944. Retrieved July 4, 2014 from http://www.sas.upenn.edu/ duckwort/images/PsychologicalScienceDec2005.pdf

Fan, X., Thompson, B., \& Wang, L. (1999). The effects of sample size, estimation methods, and model specification on SEM fit indices. Structural Equation Modeling, 6, 56-83.

Fiori, K., Antonucci, T. C., \& Cortina, K. (2006). Social network typologies and mental health among older adults.Journal of Gerontology, Series B: Psychological Sciences and Social Sciences, 61(1), 25-32.

Fredericks, J., Blumenfeld, P., \& Paris, A. (2004). School engagement Potential of the concept, state of the evidence. Review of Educational Research, 74, 59-109. Retrieved July 26, 2014 from http://www.jstor.org/stable/3516061.

Freeman, T., Anderman, L., \& Jensen, J. (2007). Sense of belonging in college freshmen at the classroom and campus levels. The Journal of Experimental Education, 75, 203-220. http://dx.doi.org/10.3200/ JEXE.75.3.203-220.

Freund, A. M., \& Baltes, P. B. (2002). Life-management strategies of selection, optimization and compensation: Measurement by self-report and construct validity. Journal of Personality and Social Psychology, 82(4), 642-662. Retrieved 29 July, 2014 from http://psycnet.apa.org/index.cfm?fa=buy.optionToBuy\&id= 2002-12744-012

Glanville, J. L., \& Wildhagen, T. (2007). The measurement of school engagement: Assessing dimensionality and measurement invariance across race and ethnicity. Educational and Psychological Measurement, 67, 1019-1041. http://dx.doi.org/10.1177/0013164406299126

Goodenow, C. (1993b). The psychological sense of school membership among adolescents: Scale development and educational correlates. Psychology in the Schools, 30, 70-90.

Griffiths, R., Horsfall, J., Moore, M., Lane, D., Kroon, V., \& Langdon, R. (2007). Assessment of health, well-being, and social connections: A survey of women living in Western Sydney. International Journal of Nursing Practice, 13(1), 3-13. http://dx.doi.org/10.1111/j.1440-172X.2006.00606.x

Hall, B. L., \& Hursch, D. E. (1982). An evaluation of the effects of a time management training program on work efficacy. Journal of Organizational Behavior Management, 3, 73-98.

Hamedani, S. (2013). The relationship between self-effciacy and self-regulation in Vocabulary acquisition of Iranian EFL learners. Journal of Academic and Applied Studies, 3(1), 20-31.

Hawkins, J. D., Catalano, R. F., Kosterman, R., Abbott, R., \& Hill, K. G. (1999). Preventing adolescent health-risk behaviors by strengthening protection during childhood. Archives of Pediatric and Adolescent Medicine, 153, 226-234.

Helmreich, R. L., \& Spence, J. T. (1978). The Work and Family Orientation Questionnaire: An objective instrument to assess components of achievement motivation and attitudes toward family and career. Catalog of Selected Documents in Psychology, 8(2).

Hutcherson, C., Seppala, E., \& Gross, J. (2008). Loving-kindness mediation increases social connectedness. Emotion, 8(5), 720-724. http://dx.doi.org/10.1037/a0013237

Ingersoll-Dayton, B., Morgan, D., \& Antonucci, T. (1997). The effects of positive and negative social exchanges on aging adults. Journals of Gerontology, Series B: Psychological Sciences and Social Sciences, 52, 190-199.

Jdaitawi, M., Motawa, A., \& Al-Nabrawi, I. (2013). Analysis of Adolescent period in Saudi Arabia: Social connectedness. Paper accepted at 7th International Technology, Education and Development Conference (INTED2013/ 4th-6th March), Valencia, Spain.

Joo, Y., Bong, M., \& Choi, H. (2000). Self-efficacy for self-regulated learning, academic self-efficacy and internet self-efficacy in web based instruction. Educational Technology Research and Development, 48(Z), 
5-17. Retrieved from http://www.nottingham.ac.uk/ ntzcl1/literature/self-efficacy/joo.pdf

Julawong, O. (2009). The relationship among social support, stigma, and coping strategies in Thai women with HIV/AIDS. Dissertation Abstracts International, 70(2-B), 940.

Kelloway, E. K. (1998). Using LISREL for structural equation modeling. Thousand Oaks: Sage Publications.

Kuhnle, C., Hofer, M., \& Kilian, B. (2010a). The relationship of value orientation, self-control, frequency of goals conflicts in school and leisure, and life-balance in adolescence. Learning and Individual Differences, 20,251-255.

Lane, J., Lane, A., \& Cockerton, T. (2003b). Prediction of academic performance from self-efficacy and performance accomplishments among master degree students. Journal of Hospitality, Leisure, Sport and Tourism Education, 2(1), 113-118.

Lee, R. M., \& Robbins, S. B. (1998). The relationship between social connectedness and anxiety, self-esteem, and social identity. Journal of Counseling Psychology, 45, 338-345.

Lee, R. M., \& Robbins, S. B. (2000). Understanding social connectedness in college women and men. Journal of Counseling and Development, 78, 484-491.

Lee, R. M., Draper, M., \& Lee, S. (2001). Social connectedness, dysfunctional interpersonal behaviors, and psychological distress: Testing a mediator model. Journal of Counseling Psychology, 48(3), 310-318. http://dx.doi.org/1O.1O37//OO22-O167.48.3.31O

Lee, R. M., Keough, K. A., \& Sexton, J. D. (2002). Social connectedness, social appraisal, and perceived stress in college women and men. Journal of Counselling \& Development, 80, 355-361.

Lefcourt, H. M. (2001a). Humor: The psychology of living buoyantly. New York: Kluwer Academic/Plenum Publishers.

Lemberger, M., \& Clemens, E. (2012). Connectedness and self-regulation as construct of the students success skills program in inner-city African American elementary students. Journal of Counseling\& Development, 90(4), 450-458. http://dx.doi.org/10.1002/j.1556-6676.2012.00056.x

Lerner, R., \& Villarruel, F. (1994). Adolescence. In T. Husen, \& T. Postlethwait (Eds.), The international encyclopedia of education (pp. 83-89). Oxford, England: Pergamon.

Little, T., Cunningham, W., Shahar, G., \& Widaman, K. (2002). To parcel or not to parcel: Exploring the question, weighing the merits. Structural Equation Modelling, 9, 151-173. http://dx.doi.org/10.1207/S15328007SEM0902_1

Litwin, H. (2001). Social network type and morale in old age. Gerontologist, 41(4), 516-524. http://dx.doi.org/10.1093/geront/41.4.516

Maehr, M. L., \& Meyer, H. A. (1997). Understanding motivation and schooling: Where we've been, where we are, and where we need to go. Educational Psychology Review, 9, 371-408.

Mansfield, C. (2010). Motivating adolescents: Goals for Australian students in secondary schools. Australian Journal of Educational \& Developmental Psychology, 10, 44-55. Retrieved from http://files.eric.ed.gov/fulltext/EJ885706.pdf

Maria, P. (2003). Achievement motivation and Mexican immigrant and Mexican-American College Students: A psychological perspective. Retrieved June 15, 2011, from http://www.lib.umi.com/dissertations/fullucit/ 3117675

McWhirter, B. T. (1990). Loneliness: A review of current literature, with implications for counseling and research. Journal of Counseling and Development, 68(4), 589-595. http://dx.doi.org/10.1002/j.1556-6676.1990.tb02521.x

Megan, L. (2009). Psychosocial factors and racial differences in blood pressure dipping. American Journal of Hypertension, 22, 584. http://dx.doi.org/10.1038/ajh.2009.73.

Miller, A. L., \& Glinski, J. (2000). Youth suicidal behavior: Assessment and intervention. Journal of Clinical Psychology, 56(9), 1131-1152.

Mooi, T. (2007). Self-efficacy and student performance in an accounting course. Journal of Financial Reporting and Accounting, 4(1), 129-146. Retrieved from http://www.emeraldinsight.com/doi/abs/10.1108/ 19852510680001586 
Necati, C., \& Sevil, F. (2010). The relation on time management skills and academic achievement of potential teachers. Educational Research Quarterly, 33(4), 3-23.

Osterman, K. F. (2000). Students' need for belonging in the school community. Review of Educational Research, 70(3), 323-367. http://dx.doi.org/10.3102/00346543070003323

Pajares, F. (1997). Current directions in self-efficacy research. In M. Maehr, \& P. R. Pintrich (Eds.), Advances in motivation and achievement. Greenwich, CT: JAI Press.

Pintrich, P., \& DeGroot, E. (1990). Motivational and self-regulated learning components of classroom academic performance. American Psychological Association, 82, 33-40.

Pittman, L., \& Richmond, A. (2007). Academic and psychological functioning in late adolescence: The importance of school belonging. The Journal of Experimental Education, 75(4), 270-288.

Ragheb, M. G., \& Beard, J. G. (1982). Measuring leisure attitude. Journal of Leisure Research, 14(2), 155-167.

Raver, C. C. (2003). Young Children, Is Emotional Development and School Readiness. Retrieved from http:// www.eric.ed.gov April 2012

Raver, C. C., \& Knitze, J. (2002). Ready to Enter: What Research Tells Policymakers About Strategies to Promote Social and Emotional School Readiness Among Three-and Four-Year-Old Children. Policy Paper. No. 3 Promoting the Emotional Well-Being of Children and Families National Center for Children in Poverty.

Resnick, M. D., Bearman, P. S., Blum, R. W., Bauman, K. E., Harris, K. M., Jones, J., . . Udry, J. R. (1997). Protecting adolescents from harm: Findings from the National Longitudinal Study on Adolescent Health. Journal of the American Medical Association, 278(10), 823-832. http://dx.doi.org/10.1001/jama.1997.03550100049038

Robert, B., \& Libbey, H. (2004). School connectedness, strengthening health and education outcomes for teenagers. Journal of School Health, 74, 7.

Robson, C. (1993). Real World research: A resource for social scientists and practitioners researcher. Blackwell, Oxford.

Sawyer, M. G., Arney, F. M., Baghurst, P. A., Clark, J. J., Graetz, B. W., Kosky, R. J., . . Zubrick, S. R. (2001). The mental health of young people in Australia: key findings from the child and adolescent component of the national survey of mental health and well-being. The Australian \& New Zealand Journal of Psychiatry, 35(6), 806-814. Retrieved from http://www.ncbi.nlm.nih.gov/pubmed/11990891

Schaps, E., Battistich, V., \& Solomon, D. (1997). School as a caring community: A key to character. In A. Molnar (Ed.), The construction of children's character. Ninety-sixth yearbook of the National Society for the Study of Education (pp. 127-139). Chicago: National Society for the Study of Education.

Schunk, D. (1990). Goal setting and self-efficacy during self-regulated learning. Educational Psychologist, 25, 71-86.

Schunk, D. H., \& Ertmer, P. A. (2000). Self-regulation and academic learning: self-efficacy enhancing interventions. In M. Boekaerts, P. R. Pintrich, \& M. Zeidner (Eds.), Handbook of self-regulation (pp. 631-649). San Diego: Academic Press.

Schunk, D. H., \& Peggy, A. E. (1999). Self-regulatory processes during computer skill acquisition: Goal and self-evaluative influences. Journal of Educational Psychology, 2, 251-260.

Schwarzer, R. (Ed.). (1992). Self-efficacy: Thought Control of Action. Washington, DC: Hemisphere.

Schwarzer, R., \& Jerusalem, M. (1995). Generalized Self-Efficacy scale. In J. Weinman, S. Wright, \& M. Johnston (Eds.), Measures in health psychology: A user's portfolio. Causal and control beliefs (pp. 35-37). Windsor, UK: NFER-NELSON.

Sekaran, U. (2003). Research Methods for business: A skill building approach. John Willey \& Sons, Ltd.

Shoda, Y., Mischel, W., \& Peake, P. K. (1990). Predicting adolescent cognitive and self-regulatory competencies from preschool delay of gratification: Identifying diagnostic conditions. Developmental Psychology, 26, 978-986.

Stacks, D. (2002). Primer of public relations research. New York: Guilford.

Stracuzzi, N., \& Mills, M. (2010). Teachers matter: Feelings of school connectedness and positive youth 
development among Coos County youth. New England.

Twenge, J., Catanese, K., \& Baumeister, R. (2002). Social Exclusion Causes Self Defeating Behavior. Journal of Personality and Social Psychology, 83(3), 606-615. http://dx.doi.org/10.1037/0022-3514.92.1.56

Weinstein, C., \& Palmer, D. R. (2002). User's manual learning and study strategies inventory (2nd ed.). Florida: H\&H Publishing.

Whittaker, S. (2008). Investigation of social connectedness in a college population and its relationship to perceived stress and health symptoms. Master thesis, University of North Florida, USA.

Williams, K. L., \& Galliher, R. V. (2006). Predicting depression and self-esteem from social connectedness, support, and competence. Journal of Social and Clinical Psychology, 25, 855-874. http://dx.doi.org/10.1521/jscp.2006.25.8.855

Witherspoon, D. W., Schotland, M., Way, N., \& Hughes, D. (2009). Connecting the dots: How connectedness to multiple contexts influences the psychological and academic adjustment of urban youth. Applied Developmental Science, 13, 199-216.

Wrosch, C., \& Freund, A. M. (2001). Self-regulation of normative and non-normative developmental challenges. Human Development, 44, 264-283.

Yusuf, M. (2011). The impact of self-efficacy, achievement motivation, and self-regulated learning strategies on students' academic achievement. Elsevier, 15(26), 23-26. http://dx.doi.org/10.1016/j.sbspro.2011.04.158

Zachariah, R. (1994). Mother-daughter and husband-wife attachment as predictors of psychological well-being during pregnancy. Clinical Nursing Research: An International Journal, 3, 371-392. Retrieved from http://www.ncbi.nlm.nih.gov/pubmed/7703869

Zimmerman, B. (2000). Attaining self-regulation: A social cognitive perspective. In M. Boekaerts, P. Pintrich, \& M. Zeidner (Eds.), Handbook of Self-Regulation. Burlington, MA: Elsevier Academic Press.

Zimmerman, B. (2008). Investigating self-regulation and motivation: Historical background, methodological developments, and future prospects. American Educational Research Journal, 45(1), 166-183. Retrieved from http://eric.ed.gov/?id=EJ788053

Zimmerman, B. J., \& Schunk, D. H. (Eds.). (1989). Self-regulated learning and academic achievement: Theory, research, and practice. New York, NY: Springer-Verlag.

Zimmerman, B. J., \& Schunk, D. H. (Eds.). (2001). Self-regulated learning and academic achievement: Theoretical perspectives (2nd ed.). Mahwah, NJ: Erlbaum.

Zimmerman, B., \& Martinez-Pones, M. (1986). Development of a structured interview for assessing student use of self-regulated learning strategies. American Educational Research Journal, 23(4), 614-628. http://dx.doi.org/10.3102/00028312023004614

\section{Copyrights}

Copyright for this article is retained by the author(s), with first publication rights granted to the journal.

This is an open-access article distributed under the terms and conditions of the Creative Commons Attribution license (http://creativecommons.org/licenses/by/3.0/). 